\title{
Feasibility study of a smoking cessation intervention in Directly Observed Therapy Short-Course tuberculosis treatment clinics in Rio de Janeiro, Brazil
}

\author{
Andrea Borges Sereno, ${ }^{1}$ Elizabeth Cristina C. Soares, ${ }^{2}$ \\ Jose Roberto Lapa e Silva, ${ }^{1}$ Anna María Nápoles, ${ }^{3}$ \\ Stella Aguinaga Bialous, ${ }^{4}$ Vera Luiza da Costa e Silva, ${ }^{5}$ \\ and Thomas E. Novotny ${ }^{6}$
}

Suggested citation

Sereno AB, Soares ECC, Lapa e Silva JR, Nápoles AM, Bialous SA, da Costa e Silva VL, et al. Feasibility study of a smoking cessation intervention in Directly Observed Therapy Short-Course tuberculosis treatment clinics in Rio de Janeiro, Brazil. Rev Panam Salud Publica. 2012;32(6):451-6.

\begin{abstract}
A pilot feasibility study was conducted to determine whether Directly Observed Therapy Short-Course (DOTS) workers could be trained to deliver smoking cessation counseling and referral interventions, identify potential barriers to a full-scale randomized controlled trial on the effectiveness of integrated smoking cessation in DOTS, and determine whether tuberculosis (TB) patients who smoke would agree to participate in such a program. DOTS providers in two Rio de Janeiro primary health clinics received 1-day training in cessation counseling. They completed pre- and post-training surveys and participated in post-program focus groups. Patients were surveyed 3 months after program completion, and semiquantitative urine assays for cotinine were used to confirm cessation. Providers' mean self-efficacy scores for cessation counseling improved significantly (advise to quit, assess readiness, assist with quitting, and arrange follow-up) from scores (on a scale of 1-5) of 2-3 pre-training to 3-4 post-training $(\mathrm{P}<0.05)$, with only ability to change motivation not significant. Providers' knowledge about cessation (withdrawal, nicotine replacement therapy, precontemplation) was low before training and did not improve after training ( $\mathrm{P}>0.1$ for all comparisons). Implementation of a smoking cessation intervention by DOTS providers in TB clinics in Brazil is feasible. Randomized controlled trials to test intervention effectiveness in reducing TB-related morbidity must include cross-training for tobacco control and TB providers. Smoking cessation in DOTS programs may be important in reducing the global burden of TB, improving the health of TB patients, and reducing TB transmission in households.
\end{abstract}

Key words Tuberculosis; smoking cessation; tobacco use cessation; Brazil.

Universidade Federal de Rio de Janeiro, Hospital Universitário Clementino Fraga Filho, Rio de Janeiro, Brazil.

2 Secretaria Municipal de Saúde e Defesa Civil do Rio de Janeiro, Gerencia de Pneumologia Sanitaria, Rio de Janeiro, Brazil.
Division of General Internal Medicine, Department of Medicine, University of California, San Francisco, California, United States of America.

4 World Health Organization, Tobacco Control Policy International, San Francisco, California, United States of America.
National Public Health School, Oswaldo Cruz Foundation, Rio de Janeiro, Brazil.

6 Graduate School of Public Health, San Diego State University, San Diego, California, United States of America. Send correspondence to: Thomas E. Novotny, tnovotny@mail.sdsu.edu 
Tuberculosis (TB) is a major global health problem, with the World Health Organization (WHO) estimating 9.4 million incident cases, 14 million prevalent cases, 1.3 million non-HIV-associated deaths, and 0.38 million additional HIVassociated TB deaths in 2009 (1). Globally, TB incidence peaked in 2004 at 142 per 100000 (95\% confidence interval, 136-151); in many WHO regions, including the Americas, it appears that halving the TB mortality rate may be possible by 2015. The WHO Stop TB Strategy and programs such as the Global Fund for AIDS, TB, Malaria have generated increased funding for TB control in recent years (US $\$ 5$ billion in 2011), but important gaps in global TB control remain, especially among special populations (HIV-infected individuals, incarcerated individuals, and smokers).

There is growing evidence concerning risks for TB morbidity and mortality associated with smoking $(2,3)$. These risks appear to be independent of the effects of alcohol use, socioeconomic status, and other potential confounders (4). In fact, the relative risk for active TB among smokers is 2.6, with a resultant global attributable fraction of $23 \%$ (5). TB mortality among smokers is likewise about double the risk among nonsmokers (relative risk 2.1) (6, 7). In addition, smoking has been found to be associated with longer sputum smear conversion time [a marker for success of TB treatment (8)] and to be an independent risk for relapse among TB patients (9). The interaction of TB with smoking is a particular concern in low- and middleincome countries with high burdens of $\mathrm{TB}$ and other infectious diseases and with increasing smoking rates $(10,11)$. Poverty and alcohol abuse often coexist with TB and smoking, further complicating the delivery of TB treatment. In addition, smoking and TB may work synergistically with HIV infection to increase risks for chronic obstructive pulmonary disease and pulmonary opportunistic infections (12).

Brazil ranks 18th worldwide in the number of TB cases reported annually, and almost 6500 new cases were reported in Rio de Janeiro city in 2008 (incidence 87/100 000) (13). In 1999, Directly Observed Therapy Short-Course (DOTS) was implemented in 6 of 34 primary health care centers (PHCs) in Rio de Janeiro and has now expanded throughout all PHCs and into family health units as part of the integrated primary care program of the Brazilian Unified Health System $(14,15)$.

Attention to smoking in TB treatment programs is uncommon (16). However, even brief cessation advice to smokers by health care providers has been shown to increase quitting (17). TB mortality and morbidity are reduced among smokers who quit compared with those who continue to smoke (18). Thus, DOTS programs might be well suited to support smoking cessation because of the high-intensity, patient-centered casemanagement approach used (19).

Adult TB patients in Rio de Janeiro have been found to have a much higher smoking prevalence than the general population (52\% versus 16\%) (20). Eversmoking prevalence was as high as $77 \%$ in a TB case-finding project conducted in a large favela in Rio de Janeiro in 2005-2006 (21). Smoking and alcohol have also been identified as important additional TB mortality risk factors in Rio de Janeiro (22). Thus, an effective, culturally appropriate smoking cessation intervention directed toward TB patients could lead to improved overall health outcomes and reduced health care costs among this high-risk group.

A pilot study was conducted in PHC clinics delivering DOTS in Rio de Janeiro in order to determine whether DOTS workers could be trained to deliver smoking cessation counseling and referral interventions, identify potential barriers to a full-scale randomized controlled trial on the effectiveness of integrated smoking cessation in DOTS, and determine whether TB patients who smoke would agree to participate in such a program.

\section{MATERIALS AND METHODS}

\section{Procedures}

The target group for cessation training included DOTS providers in two PHCs in Rio de Janeiro. These providers are nurses or auxiliary nurses who follow a physician's clinical directions on TB treatment, monitor direct administration of TB medications, and ensure clinical follow-up of patients in the PHCs. The specific skills to be addressed in the training included the standard "five $\mathrm{A}^{\prime} \mathrm{s}$ " approach to smoking cessation counseling (23):
- Ask if patient smokes (smoking status was recorded on clinic records.

- Advise patient to quit smoking.

- Assess patient's readiness to quit.

- Assist patient with quitting.

- Arrange follow-up (within the PHC).

Pre-training and immediate posttraining assessments of self-efficacy for providing cessation counseling, smoking status, and knowledge of smoking cessation were administered. The surveys were adapted from the RX for Change approach (23) in English, translated into Portuguese, back-translated, and reconciled for accuracy.

Six months after the pilot intervention, focus groups were conducted among the trained providers to collect information on barriers and feasibility of the smoking cessation intervention.

\section{DOTS patient intervention}

Two supervisory nurses (not involved in TB treatment) from the PHCs were also trained to interview $\mathrm{TB}$ patients. They offered enrollment to all new TB patients with a history of current daily smoking who reported to the PHCs between December 2008 and April 2009. The interviewers collected written, informed consent and administered a preintervention survey. Surveys were coded and names were removed to ensure confidentiality. All eligible participants were informed about on-site cessation services. The preintervention survey included questions on smoking behavior, attitudes, and intention to quit. Another questionnaire was administered after 3 months to assess the acceptability of the cessation intervention and to ascertain cessation using self-reporting as well as biological confirmation [a urine dipstick, semiquantitative cotinine test (NicAlert ${ }^{\mathrm{TM}}$, Nymox Pharmaceutical Corporation, Hasbrouck Heights, New Jersey, United States of America)] (24). Finally, a $10 \%$ random sample of patients was interviewed after clinic visits to assess their understanding of the cessation counseling provided by DOTS providers, any referral advice received, and their intention to quit.

\section{Analyses}

The Wilcoxon signed-rank test was used to evaluate changes in providers' perceived skills and self-efficacy to pro- 
vide cessation counseling. McNemar's test for paired samples was used to evaluate changes in knowledge about smoking cessation among the providers. Postprogram focus groups were audio recorded, transcribed, and analyzed to identify potential barriers to incorporat-

Because this study focused only on the feasibility of the intervention, successful smoking cessation and correlates among participating TB patients were not fully evaluated.

\section{Ethical clearance}

Institutional review board approval was obtained from five entities: the University of California, San Francisco (where the principal investigator had been appointed); the Federal University of Rio de Janeiro; the Brazilian Federal ing the cessation intervention.

Government; the municipal authority of Rio de Janeiro; and the Pan American Health Organization.

\section{RESULTS}

\section{Training feasibility}

Sixteen DOTS providers and supervising physicians were trained in smoking cessation methods. Almost all were women $(15 / 16)$, with a mean education level of 15 years and mean age of 45.8 years. Their self-rated ability to ask, advise, assess, assist, and arrange smoking cessation among their patients improved significantly between pre-training and post-training. Their self-efficacy to provide smoking cessation support also improved overall with only "ability to change motivation" not reaching statistical significance (Table 1). Knowledge

TABLE 1. Self-rated smoking cessation counseling skills and self-efficacy scores $(1=$ low, $5=$ high), pre- and post-training, primary health center tuberculosis providers, Rio de Janeiro, Brazil, $2008(n=16)$

\begin{tabular}{|c|c|c|c|c|c|}
\hline & \multicolumn{2}{|c|}{ Pre-training score } & \multicolumn{2}{|c|}{ Post-training score } & \multirow[b]{2}{*}{$P$ value $^{a}$} \\
\hline & Median & Range & Median & Range & \\
\hline \multicolumn{6}{|l|}{ Skills } \\
\hline Overall ability to help patients quit smoking & 2.5 & $2-5$ & 3 & $2-5$ & 0.047 \\
\hline Ability to ask patients whether they smoke & 3 & $1-5$ & 4 & $2-5$ & 0.001 \\
\hline Ability to advise patients to quit smoking & 3 & $2-4$ & 4 & $3-5$ & 0.001 \\
\hline $\begin{array}{l}\text { Ability to assess if patient is ready to quit } \\
\text { smoking }\end{array}$ & 2 & $1-4$ & 3 & $2-5$ & 0.007 \\
\hline Ability to assist patient with quitting & 2 & $1-4$ & 3 & $2-5$ & 0.006 \\
\hline Ability to arrange follow-up counseling & 2 & $1-4$ & 4 & $2-5$ & 0.038 \\
\hline \multicolumn{6}{|l|}{ Self-efficacy } \\
\hline Know appropriate questions to ask & 3 & $1-4$ & 4 & $1-5$ & 0.004 \\
\hline Can provide motivation & 3 & $1-5$ & 4 & $2-5$ & 0.098 \\
\hline Have the skills to assist patients & 2.5 & $1-5$ & 3 & $2-4$ & 0.047 \\
\hline Can suggest tobacco cessation to smokers & 3 & $1-5$ & 4 & $3-5$ & 0.038 \\
\hline Provide counseling when time is limited & 2.5 & $1-5$ & 4 & $2-5$ & 0.013 \\
\hline Can counsel patients not interested in quitting & 3 & $2-4$ & 4 & $2-4$ & 0.019 \\
\hline
\end{tabular}

${ }^{a}$ Wilcoxon rank sum test.

Table 2. Smoking cessation knowledge, pre- and post-training, primary health center tuberculosis providers, Rio de Janeiro, Brazil, $2008(n=16)$

\begin{tabular}{|c|c|c|c|c|c|}
\hline \multirow[b]{2}{*}{ Knowledge } & \multicolumn{2}{|c|}{ Pre-training } & \multicolumn{2}{|c|}{ Post-training } & \multirow[b]{2}{*}{$P$ value $^{\mathrm{a}}$} \\
\hline & No. & $\%$ & No. & $\%$ & \\
\hline Nicotine withdrawal symptoms & $4 / 14^{b}$ & 28.6 & $9 / 16$ & 56.3 & 0.179 \\
\hline Time for nicotine withdrawal symptoms & $5 / 16$ & 31.3 & $7 / 16$ & 43.8 & 0.479 \\
\hline Appropriate NRT use & $11 / 16$ & 68.8 & $8 / 16$ & 50.0 & 0.179 \\
\hline Successful quitting & $13 / 16$ & 81.3 & $14 / 16$ & 87.5 & 0.563 \\
\hline Weight gain due to cessation & $8 / 16$ & 50.0 & $12 / 16$ & 75.0 & 0.102 \\
\hline Correct use of NRT & $3 / 16$ & 18.8 & $5 / 16$ & 31.3 & 0.414 \\
\hline Follow-up NRT counseling & $6 / 16$ & 37.5 & $6 / 16$ & 37.5 & 1 \\
\hline Advising precontemplation patients & $11 / 16$ & 68.8 & $12 / 16$ & 75.0 & 0.654 \\
\hline
\end{tabular}

Note: NRT: nicotine replacement therapy.

${ }^{a}$ McNemar test.

${ }^{b}$ Excludes missing values. about smoking cessation was rather low before training and did not appear to improve significantly after training (Table 2).

Only 9 of the 16 trainees participated in the 6-month post-program focus groups. These providers expressed general satisfaction with the 1-day training format but mentioned that additional content could be introduced on the specific health consequences of smoking for TB patients. They also thought additional supervision during the project period would assist in supporting interventions. All stated that time to actually intervene in each clinic visit with patients was too short. The TB providers thus focused more on referrals than on actual cessation counseling. In fact, the providers reported using an "AAR" approach (ask, advise, and refer) rather than the five A's approach.

Trainees also suggested that professionals who provide smoking cessation services in PHCs should receive training about TB in order to facilitate the interaction between the two services and to reduce fear of contagion from TB patients. In one PHC, there was resistance from the smoking cessation service to include TB patients in group counseling for fear of TB infectivity. On the other hand, the DOTS trainees reported that they did not know enough about the theoretical basis for smoking cessation and that more information would have assisted them in supporting their patients' cessation efforts.

Trainees reported that addressing smoking and quitting at every visit was probably not appropriate because of patient fatigue and time constraints. However, they noted the need for a feedback system so that they would know whether their efforts were leading to their patients' cessation success. Although providers who were former smokers thought that they were able to empathize with the patients, they did not think that current smoking by providers should be a barrier to providing counseling. Providers also suggested that the smoking status of TB patients be included as a formal record in the TB program.

Finally, providers pointed out the challenges in providing TB treatment and smoking cessation services in the largely low-socioeconomic-status population affected by TB; many of these patients have additional addictions that are seen as higher priority for intervention 
during DOTS. Nevertheless, providers thought it was feasible to make smoking cessation part of overall TB treatment protocols.

\section{Cessation intervention}

During the study period, 166 patients with TB reported to the two clinics (Table 3). Of those 166 patients, $91(54.8 \%)$ were placed on DOTS; 33 of them $(36.3 \%)$ were current smokers and eligible for inclusion in the study. The final sample included 28 smokers (84.8\%) who agreed to participate in the program and who completed informed consent and baseline questionnaires. Only $20(71.4 \%)$ of the original 28 enrollees completed the follow-up questionnaire and urine testing for cotinine. Of the eight missing enrolled patients (28.5\%), some may have opted to switch to self-supervision (non-DOTS), and some may have dropped out. Of the 20 participants who completed followup, $3(15.0 \%)$ reported quitting, and 18 (90.0\%) reported being referred to cessation services. Because of small sample sizes and incomplete data on enrollees, no statistical analyses were attempted.

Twenty-four exit interviews $(85.7 \%)$ were completed during the intervention. Only 12 of 24 interviewees (50.0\%) reported receiving counseling during the previous 3 months from their TB provider. Most of these respondents knew of other resources for cessation, and of the 12 who reported receiving counsel- ing, 11 believed it was easy to understand. The mean number of smoking cessation advice episodes patients reported receiving from the DOTS providers in 3 months was 13.6.

\section{DISCUSSION}

A pilot study was conducted to test the feasibility of a smoking cessation intervention trial in DOTS clinics in Rio de Janeiro. Although TB providers thought it feasible to introduce smoking cessation interventions within a DOTS program and that such an intervention would help patients with TB treatment success and overall lung health, they also emphasized the importance of improving communications within the PHCs between smoking cessation services and the TB treatment program. The disconnect between cessation efforts and TB treatment is the most important lesson learned from this feasibility study.

The limited approach adopted by the providers in this study (AAR approach) has been recommended for use in busy clinics (25). However, this dilution of the standard approach may have had a negative impact on the cessation attempts and success of the study's patient population. There is a dose-response relation between the session length of personto-person contact and successful treatment outcomes. However, even minimal interventions lasting less than 3 minutes increase overall tobacco abstinence rates.
TABLE 3. Tuberculosis patients participating in smoking cessation program in two primary health centers, Rio de Janeiro, Brazil, $2008(n=28)$

\begin{tabular}{|c|c|c|c|c|}
\hline \multirow[b]{2}{*}{ Variable } & \multicolumn{2}{|c|}{ Catete } & \multicolumn{2}{|c|}{ Copacabana } \\
\hline & No. & $\%$ & No. & $\%$ \\
\hline Median age, years & 40 & $\mathrm{n} / \mathrm{a}$ & 44 & $\mathrm{n} / \mathrm{a}$ \\
\hline Male & 8 & 62 & 9 & 60 \\
\hline Female & 5 & 38 & 6 & 40 \\
\hline \multicolumn{5}{|l|}{ Education, years } \\
\hline$\leq 8$ & 10 & 77 & 11 & 73 \\
\hline $9-12$ & 3 & 23 & 3 & 20 \\
\hline$>12$ & 0 & 0 & 0 & 0 \\
\hline Unknown & 0 & 0 & 1 & 7 \\
\hline \multicolumn{5}{|l|}{ Marital status } \\
\hline Single/divorced & 11 & 80 & 10 & 67 \\
\hline Married/widowed/other & 2 & 15 & 5 & 33 \\
\hline Employed & 10 & 77 & 11 & 73 \\
\hline \multicolumn{5}{|l|}{ Housing } \\
\hline House/apartment & 9 & 69 & 8 & 53 \\
\hline Comodo/barracks/other & 4 & 31 & 7 & 47 \\
\hline Total enrollees & 13 & 100 & 15 & 100 \\
\hline
\end{tabular}

Note: n/a: not applicable.
Person-to-person treatment delivered for four or more sessions appears to be especially effective in increasing abstinence rates. Therefore, if feasible, DOTS providers should try to provide cessation counseling for four or more visits with individuals who are trying to quit smoking.

The provider focus groups indicated that in a more formal clinical trial more ownership of the smoking cessation intervention needs to be established within the DOTS providers' responsibilities. Thus, the methodology originally planned for this study needs to be significantly strengthened, and future implementation research is warranted. Family support, community support, and more systematic attention to monitoring and more direct evaluation of cessation counseling efforts are also needed in such intervention trials. In addition, specific attention to patients with other addictions must be considered in any planned randomized controlled trial on smoking cessation and TB.

Several problems were identified in implementing smoking cessation in $\mathrm{TB}$ clinics in Rio de Janeiro. First, not all TB patients were identified as smokers or former smokers, as recommended in the protocol. Second, actual provision of cessation counseling by TB providers was incomplete, with only 12 of $33(36.3 \%)$ smokers overall who reported receiving advice to quit. Finally, there were difficulties in connecting the patients who received brief counseling with more extensive cessation services that were available to them. A more comprehensive, focused approach needs to be developed for a formal randomized controlled trial. In order to conduct a formal randomized controlled trial involving smoking cessation in TB clinics, the following suggestions are provided:

- Additional information on tobacco use was needed by DOTS providers. Information about risks from secondhand smoke, cardiovascular disease risks, costs of smoking, and implications of smoking for lung health in general should be provided in the training program so that providers can transmit this information to $\mathrm{TB}$ patients as they offer advice on smoking cessation.

- There is a need for improved communication and teamwork between $\mathrm{TB}$ and smoking cessation programs. Although the Rio de Janeiro DOTS 
providers were trained in cessation counseling, additional leadership, monitoring, and evaluation within the PHCs are needed to ensure commitments of key professionals across programs to guarantee that the intervention is provided.

- A 1-day training program for DOTS providers on smoking cessation may not be sufficient to empower TB providers with no experience in cessation counseling to apply such interventions. Follow-up refreshers might be helpful in sustaining attention to cessation counseling by DOTS providers.

- Family and community support are needed for TB patients to ensure a smoke-free environment that can support cessation.

\section{Conclusions}

This study provides important information for planning a formal randomized controlled trial to test the effectiveness of smoking cessation interventions within DOTS programs. Although it was conducted in a setting in Rio de Janeiro with a high TB burden, the lessons learned for improving cooperation and training among smoking cessation and TB providers may be applicable across any national TB program. Smoking cessation is likely to be a critical intervention for improving general lung health and TB treatment outcomes in countries throughout the Americas where the epidemics of TB and tobacco use coexist. However, additional clinical research is needed to assess the most effective way to integrate TB treatment and smoking cessation. The teachable moment implied in addressing smoking cessation in TB settings cannot be ignored; it is applicable no matter what the national TB burden, as all those who smoke and who have TB may suffer excessive morbidity, mortality, and TB treatment failure. Smoking cessation in DOTS programs makes sense both for the individual patient and as an important public health intervention to prevent the spread of TB.

Acknowledgment. This project was funded by a grant from Health Canada through the World Health Organization's Tobacco Free Initiative.

\section{REFERENCES}

1. World Health Organization. Global tuberculosis control: WHO Report 2010. WHO/ HTM/TB/2010.7. Geneva: WHO; 2010.

2. Lin $\mathrm{HH}$, Ezzati M, Murray M. Tobacco smoke, indoor air pollution and tuberculosis: a systematic review and meta-analysis. PLoS Med. 2007;4(1):e20.

3. Davies PD, Yew WW, Ganguly D, Davidow AL, Reichman LB, Dheda K, et al. Smoking and tuberculosis: the epidemiological association and immunopathogenesis. Trans R Soc Trop Med Hyg. 2006;100(4):291-8.

4. World Health Organization. A WHO/The Union monograph on TB and tobacco control: joining efforts to control two related global epidemics. WHO/HTM/TB/2007.390. Geneva: WHO; 2007.

5. Commission on Social Determinants of Health Priority Public Health Conditions Knowledge Network. Scoping paper: priority public health conditions. Geneva: WHO; 2007. Available from: http://www.who. int/social_determinants/resources/pphc scoping_paper.pdf Accessed 26 January 2010.

6. Slama K, Chiang CY, Enarson DA, Hassmiller K, Fanning A, Gupta P, et al. Tobacco and tuberculosis: a qualitative systematic review and meta-analysis. Int J Tuberc Lung Dis. 2007;11:1049-61.

7. Bates MN, Khalakdina A, Pai M, Chang L, Lessa F, Smith KR. Risk of tuberculosis from exposure to tobacco smoke: a systematic review and meta-analysis. Arch Intern Med. 2007;167:335-42.

8. Guler M, Unsal E, Dursun B, Aydin O, Capan $N$. Factors influencing sputum smear and culture conversion time among patients with new case pulmonary tuberculosis. Int J Clin Pract. 2007;61:231-5.
9. Thomas A, Gopi PG, Santha T, Chandrasekaran V, Subramani $\mathrm{R}$, Selvakumar N, et al. Predictors of relapse among pulmonary tuberculosis patients treated in a DOTS programme in South India. Int J Tuberc Lung Dis. 2005;9(5):556-61.

10. Giovino GA, Mirza SA, Samet JM, Gupta PC, Jarvis MJ, Bhala N, et al. Tobacco use in 3 billion individuals from 16 countries: an analysis of nationally representative cross-sectional household surveys. Lancet. 2012;380(9842):668-79.

11. Novotny TE. Smoking cessation and tuberculosis: connecting the DOTS. Int J Tuberc Lung Dis. 2008;12:1103

12. van Zyl Smit RN, Pai M, Yew WW, Leung CC, Zumla A, Bateman ED, et al. Global lung health: the colliding epidemics of tuberculosis, tobacco smoking, HIV and COPD. Eur Respir J. 2010;35:27-33.

13. Municipio do Rio de Janeiro. Boletim informativo do programa de controle da tuberculose do município do Rio de Janeiro. Rio de Janeiro: Municipio do Rio de Janeiro; 2008.

14. Soares EC, Pacheco AG, Mello FC, Durovni $\mathrm{B}$, Chaisson RE, Cavalcante SC. Improvements in treatment success rates with directly observed therapy in Rio de Janeiro City. Int J Tuberc Lung Dis. 2006;10(6):690-5.

15. Mohan CI, Bishai D, Cavalcante S, Chaisson RE. The cost-effectiveness of DOTS in urban Brazil. Int J Tuberc Lung Dis. 2007;11(1):27-32.

16. Slama K, Chiang CY, Enarson DA. Introducing brief advice in tuberculosis services. Int $\mathrm{J}$ Tuberc Lung Dis. 2007;11(5):496-9.

17. Secades-Villa R, Alonso-Pérez F, GarcíaRodríguez O, Fernández-Hermida JR. Effectiveness of three intensities of smoking cessation treatment in primary care. Psychol Rep. 2009;105(3 Pt 1):747-58.
18. Wen CP, Chan TC, Chan HT, Tsai MK, Cheng TY, Tsai SP. The reduction of tuberculosis risks by smoking cessation. BMC Infect Dis. 2010;10:156.

19. Hopewell PC, Pai M, Maher D, Uplekar $\mathrm{M}$, Raviglione MC. International standards for tuberculosis care. Lancet Infect Dis. 2006;6(11):710-25.

20. Cavalcante SC, Saraceni V, Cohn S, Soares ECC, Barnes GL, Golub JE, et al. Tuberculosis and smoking among patients entering a DOTS program in Rio de Janeiro City, Brazil. Int J Tuberc Lung Dis. 2010;14(Suppl 2):S177.

21. Miller AC, Golub JE, Cavalcante SC, Durovni B, Moulton LH, Fonseca Z, et al. Controlled trial of active tuberculosis case finding in a Brazilian favela. Int J Tuberc Lung Dis. 2010;14(6):720-6.

22. Chiang CY, Slama K, Enarson DA. Associations between tobacco and tuberculosis. Int J Tuberc Lung Dis. 2007;11(3):258-62.

23. Fiore $M C$, Jaén $C R$, Baker $T B$, Bailey WC, Benowitz NL, Curry SJ, et al. Treating tobacco use and dependence: 2008 update. Clinical practice guidelines. Rockville, Maryland: U.S. Department of Health and Human Services; 2008.

24. NicAlert: accurate measurement of nicotine consumption and tobacco exposure. Available from: http://www.nymox.com/default.action?itemid $=47$ Accessed 31 October 2012.

25. Schroeder SA. What to do with a patient who smokes. JAMA. 2005;294(4):482-7.

Manuscript received on 12 April 2012. Revised version accepted for publication on 14 August 2012. 
RESUMEN Se llevó a cabo un estudio piloto de factibilidad para determinar si se podría capacitar a los trabajadores que administran el Tratamiento Acortado Directamente Observado (DOTS, por sus siglas en inglés) con objeto de que ofrecieran orientación para el

Estudio de factibilidad de una intervención para el abandono del hábito de fumar en consultorios de Río de Janeiro, Brasil, donde se administra el Tratamiento Acortado Directamente Observado de la tuberculosis abandono del hábito de fumar e intervenciones de derivación, detectar las barreras potenciales a un ensayo controlado aleatorizado en gran escala sobre la eficacia de la integración en el DOTS del abandono del hábito de fumar, y determinar si los pacientes fumadores con tuberculosis estarían de acuerdo en participar en este tipo de programa. Los proveedores del DOTS en dos dispensarios de atención primaria de Río de Janeiro recibieron capacitación durante un día sobre orientación para el abandono del hábito de fumar, cumplimentaron encuestas previas y posteriores a la capacitación, y participaron en grupos de discusión posteriormente al programa. Se entrevistó a los pacientes tres meses después de la finalización del programa y, para confirmar la cesación, se llevaron a cabo estudios semicuantitativos de cotinina en orina. Las puntuaciones medias de competencia personal de los proveedores para la orientación de cesación (aconsejar el abandono del hábito, evaluar la disponibilidad, apoyar el proceso de cesación y organizar el seguimiento) mejoraron significativamente desde puntuaciones (en una escala de 1 a 5) de 2 a 3 antes de la capacitación a puntuaciones de 3 a 4 después de la capacitación $(P<0,05)$, únicamente sin mejoras significativas en la capacidad para modificar la motivación. Los conocimientos de los proveedores acerca de la cesación (abstención, tratamiento sustitutivo con nicotina, preconsideración) eran escasos antes de la capacitación y no mejoraron después de esta ( $P>0,1$ para todas las comparaciones). La implantación de una intervención para el abandono del hábito de fumar por parte de los proveedores del DOTS en los consultorios antituberculosos del Brasil resulta factible. Los ensayos controlados aleatorizados para evaluar la eficacia de la intervención en la reducción de la morbilidad relacionada con la tuberculosis deben incluir la capacitación interdisciplinaria de los proveedores de servicios de control del tabaco y de tratamiento de la tuberculosis. La incorporación del abandono del hábito de fumar en los programas de DOTS podría ser importante para reducir la carga mundial de tuberculosis, mejorar la salud de los pacientes con tuberculosis y limitar la transmisión de la tuberculosis en los hogares.

Palabras clave Tuberculosis; cese del tabaquismo; cese del uso de tabaco; Brasil. 